\title{
O processo de sucessão presidencial em cooperativas de crédito: um estudo de caso
}

\author{
Josiele Maria Fão ${ }^{1}$ \\ Felipe Cavalheiro Zaluski ${ }^{2}$ \\ Fabiana Zanardi ${ }^{3}$
}

Resumo: O presente estudo busca analisar as percepções de gestores sobre o processo de sucessão presidencial em cooperativas de crédito. Para isso, buscou-se, em primeiro lugar, identificar e analisar os quesitos formulados no processo de seleção e avaliação de candidatos ao cargo de presidente da Cooperativa de Crédito Sicredi na região do Alto Uruguai/RS. Além disso, pretendeu-se conhecer o método utilizado e o perfil exigido pela cooperativa nesse processo sucessório. A pesquisa caracteriza-se como qualitativa e descritiva, realizada por meio de entrevistas semiestruturadas com os gestores da cooperativa. Conforme apontam os resultados, o processo sucessório na cooperativa de crédito em estudo refletiu os valores compartilhados entre o indivíduo e a empresa, reafirmando que essa relação é a principal fonte de eficácia pessoal e organizacional. Cabe ressaltar que a forma de sucessão é inovadora para esse tipo de instituição e traz muitos pontos positivos, já que desperta nos colaboradores o interesse em evoluir e o sentimento de valorização por parte da instituição.

Palavras-chave: Cooperativismo. Cooperativas de crédito. Sucessão.

\section{The process of presidential succession in credit cooperatives: a case study}

\begin{abstract}
This study seeks to analyze the perceptions of managers in the process of presidential succession in credit unions, which had presidential transition of managers. To this end, we first sought to identify and analyze the requirements used in the selection and evaluation process of candidates for successor to the position of president of the Sicredi Alto Uruguai/RS Credit Cooperative. In addition, it was intended to know the method used and the profile that the cooperative seeks in this succession process. The research is characterized as qualitative and descriptive, conducted through semi-structured interviews with managers of the cooperative. As a result, the succession process in the credit union studied reflected the values shared between the individual and the company, reaffirming that this relationship is the main source of personal and organizational effectiveness. It is also noteworthy that the form of succession is innovative for this type of institution and that brings with it many positive points as it arouses in employees the interest of evolution and the feeling of appreciation by the institution.
\end{abstract}

Keywords: Cooperatives. Succession. Credit unions.

\section{Introdução}

O processo sucessório acontece inevitavelmente em todos os tipos de organizações, de forma planejada, ou apenas por necessidade, nesse caso, sem estudo prévio. Algumas organizações estabelecem critérios e se programam para que o sucedimento ocorra de forma programada, com o objetivo de que a

${ }^{1}$ Universidade Regional do Noroeste do Estado do Rio Grande do Sul (UNIJUÍ). Mestre em Desenvolvimento Regional. E-mail: josielefao@gmail.com.

2Universidade Federal de Santa Maria (UFSM). Doutorando em Administração. E-mail: felipezaluski@,hotmail.com.

${ }^{3}$ Universidade Regional do Noroeste do Estado do Rio Grande do Sul (UNIJUÍ). Mestre em Desenvolvimento Regional.E-mail: fab.zan@hotmail.com. 
instituição não sofra perdas de aprendizados quanto ao gerenciamento ao longo das mudanças (PEISE; WOOTEN, 1983).

No entanto, outras empresas são tomadas pela necessidade de sucessão da liderança da empresa sem ao menos ter planejado esse acontecimento. O que se pode afirmar é que esse acontecimento é uma realidade organizacional que não pode ser evitada e representa uma estratégia importante, visto que está fundamentalmente relacionada à influência na gestão (VIDIGAL, 1996). Os impactos causados no desempenho da organização estão diretamente vinculados ao planejamento dessas mudanças.

Conforme Hall (1986), planejar o processo sucessório é uma perspectiva que reflete uma fragilidade na área estratégica dos recursos humanos das organizações. Afirma ainda que a ausência do pensar na sucessão dentro da estratégia organizacional provoca consequências que podem repercutir no futuro da empresa de maneira não tão positiva. Mesmo operando com uma gestão diferenciada, nos moldes de uma empresa particular, as cooperativas necessitam de um planejamento para tornar efetiva a tomada de decisões e garantir um futuro seguro aos associados.

No contexto das cooperativas de crédito, existem regulamentação e critérios de funcionamento que normatizam as operações. Essas normas são ditadas pelo Banco Central do Brasil (BACEN). As cooperativas de crédito são autorizadas e supervisionadas pelo Banco Central, ao contrário do que ocorre com outros ramos do cooperativismo, tais como transporte, educação e agropecuária. A Lei n ${ }^{\circ}$ 5.764/1971 instituiu a Política Nacional de Cooperativismo, que define o regime jurídico das sociedades cooperativas, suas características e os princípios do cooperativismo (BACEN, 2019). Os bancos cooperativos subordinam-se à legislação e à regulamentação aplicáveis aos bancos comerciais e aos bancos múltiplos em geral.

Diante do exposto, a problemática da pesquisa é: Quais as percepções dos gestores no processo de sucessão presidencial em uma cooperativa de crédito? O objetivo do presente estudo é, portanto, analisar as percepções dos gestores no processo de sucessão presidencial em cooperativa de crédito que passou por transição de gestores. Para isso, em primeiro lugar, buscou-se identificar e analisar os quesitos usados no processo de seleção e avaliação de candidatos ao cargo de presidente da Cooperativa de Crédito Sicredi Alto Uruguai/RS. Além disso, pretendeu-se conhecer o método utilizado e o perfil exigido pela referida cooperativa nesse processo sucessório.

$\mathrm{O}$ artigo está dividido em três seções. A primeira apresenta o referencial teórico utilizado para análise e compreensão teórica do estudo. Após, apresentam-se a metodologia adotada para a coleta, a análise e interpretação dos dados do estudo. Em seguida, apontam-se os resultados do estudo. Por fim, apresentam-se as conclusões do estudo.

\section{Cooperativismo e gestão em cooperativas de crédito}

O cooperativismo, nos seus mais diversos ramos de atividade, tem despertado o interesse de muitos pesquisadores devido a alguns aspectos específicos dessa modalidade de organização. Entre esses aspectos 
estão a preocupação em manter as práticas de decisões mais democráticas e a conjugação de esforços, cuja atenção se concentra na necessidade de aliar resultados empresariais com expectativas sociais, estas relacionadas com a problemática do desemprego ou do subemprego, com a geração de emprego e renda e o desenvolvimento regional sustentável (LIMA, 2008).

Historicamente, é possível inferir, a experiência brasileira no cooperativismo de crédito iniciou-se em 1902, quando foi criada a "Sociedade Cooperativa Caixa de Economia e Empréstimos de Nova Petrópolis". A partir dessa iniciativa, surgiram inúmeras outras que, em virtude do foco eminentemente rural, eram subordinadas ao Ministério da Agricultura (SOARES; MELO SOBRINHO, 2008).

Segundo Gawlak e Ratzke (2010), no Brasil, o cooperativismo teve início na área urbana após a criação da primeira cooperativa de consumo na cidade de Ouro Preto (MG), no ano de 1889, denominada Sociedade Cooperativa Econômica dos Funcionários Públicos de Ouro Preto. Posteriormente, expandiuse para os Estados de Pernambuco, Rio de Janeiro, São Paulo, Rio Grande do Sul e Minas Gerais. No ano de 1902, surgiram as cooperativas de crédito no Rio Grande do Sul, por iniciativa do padre suíço Theodor Amstadt. As cooperativas no meio rural despontam em 1906, idealizadas por produtores agropecuários, em várias localidades, principalmente em comunidades de imigrantes alemães, holandeses, italianos, poloneses e japoneses e outras, dando forma ao cooperativismo hoje existente no país.

Tratando-se do Brasil, após a publicação da Resolução do Conselho Monetário Nacional no 3.859 de 27 de maio de 2010, as Cooperativas de Crédito são obrigadas a implantar a Governança Corporativa em sua gestão pelo Banco Central do Brasil (BACEN, 2010). Além disso, as Cooperativas de Crédito são instituições financeiras não bancárias, constituídas pela vontade de associados que investem seus recursos na formação do capital inicial e buscam o crescimento contínuo desses recursos (CRÚZIO, 2005). Apesar de essas instituições não terem por objetivo o "lucro", os resultados obtidos podem levar à distribuição das sobras e, consequentemente, à satisfação dos associados. Contam, portanto, com a melhoria dos controles internos para atingir a confiabilidade nas informações contábeis, o atendimento às normas e o cumprimento da legislação (SCHARDONG, 2002).

Diante disso, a legislação regulamenta a forma de constituição, a autorização para início de atividades, as alterações estatutárias e o cancelamento de autorização para funcionamento das cooperativas de crédito (CHAVES, 2009). Essa necessidade de alinhar os interesses individuais é uma prática em empresas que almejam um crescimento ordenado e sempre evoluir conforme o mercado. O propósito, dessa forma, é um só, está definido nos seus valores, missão e visão. Consequentemente a vivência do cooperativismo é a principal veia de sustentação do sistema (SOARES; MELO SOBRINHO, 2008).

\section{Sucessão nas entidades cooperativas}

A sucessão nas organizações ocorre de forma planejada ou não, é uma realidade que vai refletir no futuro das próximas gestões dentro da empresa. O processo de sucessão planejado vem como meio de minimizar os impactos gerados pela troca de líderes, sendo que o principal objetivo, o crescimento da empresa, deve ficar em primeiro plano, e não o crescimento pessoal de algumas peças dentro da 
organização (IP; JACOBS, 2006). Essa sucessão é mais notável em empresas familiares e sempre ocorre de pais para filhos ou de gerações para gerações. Ip e Jacobs (2006) ainda ressaltam que não existe um modelo definido de sucessão, porém eles identificaram três ações que seriam a sustentação desse processo: 1 - Suporte e preparação dos potenciais sucessores nos diferentes e múltiplos aspectos associados ao modelo de negócio; 2 - Desenvolvimento de um plano sucessório que contemple o período antecedente a sucessão, o momento da sucessão e os consequentes a ela; 3 - Adoção de métodos válidos cientificamente que tratem de cada um dos momentos e dos aspectos citados acima.

A dinâmica de sucessão é apresentada revestindo-se de duas perspectivas: a primeira, como um processo de decisão pontual e específica, tomada de momento da vacância de uma posição; a segunda, como um processo marcado pela adoção de práticas que busquem identificar, por meio de critérios, registros e acompanhamento, potenciais candidatos a determinadas posições no futuro (ROTTER, 2013). $\mathrm{Na}$ segunda perspectiva, assume-se a relevância de um processo de planejamento sucessório, cujo objetivo é antecipar-se à necessidade das organizações, principalmente para o médio e longo prazos, de maneira a preparar e contar com um excedente de potenciais candidatos a posições que exigem tal atenção (ROTHWELL et al., 2005).

Sucessão é "acima de tudo, preparar as pessoas mais indicadas para todas as funções-chave de uma empresa, inclusive para o seu Conselho de Administração" (IBGC, 2011, p. 9). Pode-se dizer ainda que "independente de sua forma societária, e de ser companhia fechada ou aberta, toda organização deve ter um planejamento de sucessão" (IBGC, 2011, p. 9). O ideal seria que houvesse uma cultura dessa sucessão, em que os processos fossem pré-definidos como algo contínuo, que vai acontecer em determinado período, não como algo que acontece eventualmente.

Conforme consta no IBGC (2011, p. 9) o planejamento de sucessão não deve existir ocasionalmente, mas estar alinhado com os objetivos estratégicos da organização e "sustentar a maneira pela qual ela pretende evoluir para atingir suas metas de crescimento, rentabilidade e responsabilidade econômica, social e ambiental". Segundo a $\operatorname{ABRAPP}(2017$, p. 8), é importante a comunicação dentro das organizações durante o processo de sucessão, pois "a comunicação nas organizações é uma das formas mais eficazes da corporação sobreviver e prosperar no mercado competitivo atual".

A pesquisa de Albarello et al. (2017) teve por objetivo estudar os programas e ações sociais desenvolvidos pela Cooperativa Sicredi Alto Uruguai/RS e sua contribuição para o desenvolvimento regional, sob a ótica da história e princípios do cooperativismo de crédito. Adotou-se nesta investigação a metodologia do estudo qualitativo e da pesquisa bibliográfica (teórica), aliada ao estudo de caso da cooperativa Sicredi Alto Uruguai/RS. Os resultados indicam que os programas e ações sociais realizadas primam pela formação, informação e educação, e somente poderão ser realizadas se houver um suporte financeiro. Tais ações contribuem com o desenvolvimento regional à medida que proporcionam o acesso dos associados e demais indivíduos da comunidade a projetos que promovem o crescimento individual e coletivo, pessoal e profissional, com o pressuposto de que, na gestão da cooperativa, busca-se o equilíbrio entre o econômico e o social. 
Hümmelgen (2016) evidenciou como as ideias cooperativistas nascidas com a Revolução Industrial estão presentes e ainda influenciam as sociedades. Metodologicamente, a pesquisa baseia-se em um estudo teórico com a pesquisa bibliográfica. Segundo os resultados, constata-se que a economia solidária, na qualidade de organização econômica, visa à estabilização das cooperativas como uma forma de integrar as diversas fases da cadeia produtiva, de maneira solidária e coletiva. Assim, o artigo mostra de que maneira os princípios cooperativistas diferem do pensamento capitalista consolidado, e analisa a cooperação tal qual uma ideia de solidariedade e valorização do ser humano.

\section{Metodologia}

A abordagem adotada para a realização do estudo classifica-se como qualitativa e descritiva dos dados (LAKATOS, 2017). A pesquisa qualitativa é definida por aquilo que não pode ser mensurável, pois a realidade e o sujeito são elementos indissociáveis nas análises (SANTOS, 2007). Na pesquisa descritiva, normalmente, parte-se de um problema constatado em alguma realidade, natural ou cultural, coletam-se informações, bibliográficas ou não, analisam-se as variáveis envolvidas, efetua-se uma descrição detalhada dos fenômenos em estudo (LAKATOS, 2017).

A pesquisa caracteriza-se ainda como estudo de caso. O estudo de caso consiste em coletar e analisar informações sobre determinado indivíduo, um grupo ou comunidade, para estudar aspectos variados que sejam objeto da pesquisa (YIN, 2010). A coleta de dados baseou-se na pesquisa bibliográfica e entrevistas semiestruturadas (LAKATOS, 2017). A pesquisa bibliográfica coloca o pesquisador em contato com as publicações existentes: livros, revistas, periódicos e artigos científicos, jornais, monografias, dissertações, teses, internet (GIL, 2002).

O caso escolhido para a realização do estudo é a Cooperativa de Crédito Alto Uruguai/RS, localizada na cidade de Rodeio Bonito/RS. Realizaram-se quatro entrevistas semiestruturadas, uma aplicada com a atual presidente, com o objetivo de, entre outras informações, saber como ocorreu o último processo de sucessão nessa cooperativa; outras três, entre colaboradores que participam do processo atual de sucessão.

As entrevistas foram gravadas, com o consentimento dos entrevistados, e transcritas, para facilitar análises posteriores. Os resultados encontrados são apresentados na próxima seção.

\section{Análise e discussão dos resultados}

O cooperativismo de crédito no Brasil surgiu em 28 de dezembro de 1902, na localidade de Linha Imperial, município de Nova Petrópolis - Rio Grande do Sul, atual Sicredi Pioneira - RS. Em setembro de 1925, ocorreu a criação da primeira Central de Caixas Rurais, denominada União Popular do Rio Grande do Sul, que reuniu sessenta e seis cooperativas até 1964. Em 1967, essa central foi transformada na Cooperativa de Crédito Sul Rio-Grandense, atual Sicredi União Metropolitana. Entre 1964 e 1980, com a aprovação da reforma bancária - Lei n 4.595/1964 - e a institucionalização do crédito rural - Lei $n^{\circ}$ 4.829/1965, as restrições normativas e a perda de competitividade fazem desaparecer mais de cinquenta 
cooperativas de crédito no Rio Grande do Sul, mais precisamente no período compreendido entre 1970 e 1980 (PEREIRA, 2012).

Depois disso, muitos relatos surgiram em prol do desenvolvimento do cooperativismo na região, em 10 de julho, por decisão de todas as cooperativas, a Cocecrer/RS e suas filiadas passam a adotar a marca Sicredi, unificando a identidade de todas as cooperativas do Sistema, em representação ao Sistema de Crédito Cooperativo (SCHNEIDER, 2014).

No ano de 1981, agricultores viviam momentos econômicos difíceis, motivo que levou produtores a montar uma cooperativa. Constitui-se, portanto, no município de Rodeio Bonito, a primeira cooperativa de crédito da região, a Cooperativa do município de Rodeio Bonito (CREDIRODEIO), com o apoio da Cooperativa de Produção de Rodeio Bonito (COOPERODEIO).

A caminhada era difícil, pois os grandes produtores contavam com o apoio das grandes instituições financeiras, possuindo, assim, poder de compra e venda das commodities e dos insumos. No ano de 1991, ainda com o apoio da COOPERODEIO, a CREDIRODEIO iniciou a busca por associados de cidades vizinhas. Na cidade de Pinhal, distante $5 \mathrm{~km}$, montaram a primeira unidade de atendimento para essa expansão, denominada, no ano de 1992, de Sicredi Rodeio Bonito. A partir dá, o movimento cooperativista de crédito da região alavancou, de modo que, nos anos seguintes, surgiram mais três unidades de atendimento na região: em Novo Tiradentes, Cerro Grande e Ametista do Sul. Dessa forma, verificadas as vantagens do negócio para todos, surgiu outra cooperativa de crédito com o apoio da COOTRIFRED, a CREDIFRED. Instalada na cidade vizinha de Frederico Westphalen, essa Cooperativa integrou-se ao sistema Sicredi alguns anos depois. A partir daí o crescimento foi grandioso. A prova disso é a abertura de agências no estado de Minas Gerais, em 2019. Hoje a cooperativa de crédito Alto Uruguai possui vinte e oito agências estruturadas dentro do padrão Sicredi (SICREDI, 2016).

\section{Contexto do processo de sucessão na cooperativa de crédito}

Com o objetivo de facilitar o entendimento sobre sucessão, é apresentado a seguir, um resumo da política de sucessão adotada pelas Cooperativas Singulares de Crédito integrantes do Sistema de Crédito Cooperativo (Sicredi) para os cargos de alta administração (posição de Presidente do Conselho de Administração e dos membros da Diretoria). Na política de sucessão, o processo de preparação de sucessores para a alta administração compreende as seguintes etapas: recrutamento, seleção e avaliação, retenção, treinamento e eleição.

As etapas seguem uma ordem cronológica, inicia-se com o planejamento de quem será sucedido, até a indicação dos candidatos à presidência pelo Conselho de Administração. Após esse breve esclarecimento sobre o processo, apresentam-se os dados obtidos na pesquisa realizada por meio do questionário. Inicialmente é possível observar o perfil dos quatro entrevistados: 
Quadro 1 - Perfil dos entrevistados

\begin{tabular}{|c|c|c|c|c|}
\hline Questões & Entrevistado A & Entrevistado B & Entrevistado C & Entrevistado D \\
\hline Sexo & Masculino & Feminino & Masculino & Masculino \\
\hline Faixa etária & 31 a 40 anos & 41 a 50 anos & 31 a 40 anos & ano anos \\
\hline Formação & $\begin{array}{c}\text { Graduação em } \\
\text { Ciências Contábeis } \\
\text { e especialização em } \\
\text { Finanças. }\end{array}$ & $\begin{array}{c}\text { Graduação em } \\
\text { Administração, } \\
\text { especialização em } \\
\begin{array}{c}\text { Controladoria e MBA } \\
\text { em Finanças. }\end{array}\end{array}$ & $\begin{array}{c}\text { Administração e } \\
\text { MBA em } \\
\text { Inteligência de } \\
\text { negócios. }\end{array}$ & $\begin{array}{c}\text { Graduação em Ciências } \\
\text { Contábeis, especialização } \\
\text { em Gestão de Custos } \\
\text { Controladoria e MBA em } \\
\text { Inteligência Empresarial. }\end{array}$ \\
\hline $\begin{array}{c}\text { Há quanto } \\
\text { tempo é } \\
\begin{array}{c}\text { colaborador da } \\
\text { cooperativa? }\end{array}\end{array}$ & 26 anos & 20 anos & 11 e 6 meses \\
\hline
\end{tabular}

Fonte: Elaborado pelos autores (2019).

No Quadro 1, é possível observar que os gestores são, em sua maioria, do sexo masculino. A faixa etária varia de 31 a 50 anos. Todos possuem uma especialização ou MBA voltado para a área financeira e de negócios. Tal formação sugere capacitação técnica para o cargo e conhecimento teórico da área administrativa. O tempo de atuação na instituição varia entre 11 e 26 anos. Nesse período, a maioria desempenhou distintos cargos, o que comprova um conhecimento profundo da organização.

Com base nessas informações, pode-se fazer a seguinte leitura: além do conhecimento teórico, os gestores possuem conhecimento prático e, consequentemente, capacitação para o desempenho do papel de gestor da instituição.

Quadro 2 - Motivos para participar do processo de seleção a sucessor

\begin{tabular}{|c|c|}
\hline \multicolumn{2}{|c|}{$\begin{array}{c}\text { Quais os principais motivos para sua participação no processo de seleção para candidato a sucessor na gestão da } \\
\text { cooperativa? }\end{array}$} \\
\hline $\begin{array}{l}\text { Crescimento pessoal e } \\
\text { profissional. }\end{array}$ & Citado 3 vezes \\
\hline $\begin{array}{l}\text { Porque acredita que tem potencial } \\
\text { e conhecimento para compartilhar } \\
\text { com a cooperativa. }\end{array}$ & Citado 4 vezes \\
\hline $\begin{array}{l}\text { Melhoria da qualidade de vida da } \\
\text { família. }\end{array}$ & - \\
\hline $\begin{array}{l}\text { Crescimento e valorização na } \\
\text { cooperativa. }\end{array}$ & Citado 3 vezes \\
\hline $\begin{array}{l}\text { Indicação pelos colegas e } \\
\text { consenso da atual gestão. }\end{array}$ & - \\
\hline $\begin{array}{l}\text { Tempo de atuação da cooperativa, } \\
\text { conhecimento e bom } \\
\text { relacionamento com cooperados. }\end{array}$ & Citado 1 vez \\
\hline Outro & $\begin{array}{l}\text { Acredito que todo o aprendizado que adquiri desde a fundação da Cooperativa } \\
\text { até os projetos atuais, atuando em praticamente todas as áreas administrativas, } \\
\text { comerciais e estratégicas, muito contribuirá para o desempenho da função e } \\
\text { crescimento da cooperativa. }\end{array}$ \\
\hline
\end{tabular}

Fonte: Elaborado pelos autores (2019).

A questão que trata dos motivos para participar do processo de seleção para candidato a sucessor na gestão da cooperativa permitiu aos respondentes marcar mais de uma alternativa e trouxe uma opção 
de resposta livre. Todos assinalaram que "acreditam que tem potencial e conhecimento para compartilhar com a cooperativa". Essa afirmativa expõe um dos princípios do cooperativismo, a Gestão democrática, que pressupõe a atuação responsável de todos os membros.

Mesmo o respondente que marcou a alternativa "Tempo de atuação da cooperativa, conhecimento e bom relacionamento com cooperados" e o que escreveu no item "outro" sobre seu conhecimento nas distintas áreas da instituição situam os valores do cooperativismo e da autoatualização (self-actualization) no topo da pirâmide das necessidades. Profissionais com elevado nível de conhecimento e de experiência, que querem ser reconhecidos por esses atributos, bem como utilizá-los para melhorar o meio em que se inserem, têm consciência de como podem contribuir com a empresa e de que maneira isso lhes trará satisfação pessoal.

Quadro 3 - Desafios pessoais enfrentados

Quais os principais desafios pessoais que enfrentou?

A - Visão estratégica conectada com o mercado e com o futuro do mercado financeiro.

B - Meus principais desafios nesta caminhada foram especialmente as vivências dentro da Cooperativa, muitas oportunidades apareceram e em cada uma um novo e grande desafio, sempre acreditei na minha intuição e segui os alinhamentos da Instituição, assim continuamos firmes em conduzir nossa missão, hoje à frente da gestão de equipes e agência.

C - Minha trajetória profissional foi construída dentro da Instituição, iniciando em 1993, por ocasião da fundação da Cooperativa de Crédito Rural de Frederico Westphalen - CrediFred, que mais tarde (1996) foi incorporada pelo Cooperativa de Crédito de Rodeio Bonito - CrediRodeio, formando a Sicredi Alto Uruguai RS e a partir de 2018 também com região de atuação em Minas Gerais. Atuei em diversas funções dentro da Cooperativa e em diversos municípios como Gerente de Unidade de Atendimento, Assessoria de Negócios contemplando 50\% dos municípios da região de atuação da Cooperativa e nos últimos 4 anos compondo a Diretoria Executiva, na área de Operações. D - Acredito que, pra mim, o grande desafio ao me colocar em um processo de seleção como este é estar preparado psicologicamente para os momentos de análise por parte da consultoria, para os feedbacks e estar convicto daquilo que pode acontecer nesse processo e estar preparado para os dois cenários, ser ou não ser o indicado.

Fonte: Elaborado pelos autores (2019).

O Quadro 3 mostra uma questão aberta, em que os respondentes deveriam expor os desafios pessoais enfrentados. Chamam atenção a visão estratégica, as vivências, oportunidades, a atuação, alinhada aos valores institucionais, em diferentes funções. Esses itens apontam o comprometimento dos colaboradores com o clima organizacional, um modo de vida integrado aos valores dentro da instituição. Foi citado ainda o preparo psicológico para o processo. Além de importante, esse item demonstra a vontade de participar desse processo de maneira efetiva e determinada. 
Quadro 4 - Percepção dos valores da cooperativa no processo

Como você percebe os valores da cooperativa representados neste processo, missão, visão e valores?

A - Pela construção do processo de forma profissional e transparente aos participantes das etapas da avaliação.

B - Principalmente pelo fato de a oportunidade ocorrer internamente, de forma a promover o crescimento na própria base de colaboradores.

C - A percepção da missão, visão, valores e princípios ficou demonstrada no processo conduzido pela Cooperativa. $\mathrm{O}$ assunto foi discutido por ocasião das reuniões e assembleias de núcleo e o processo construído com a participação dos Coordenadores de Núcleos e Conselheiros de Administração. Toda a estruturação foi compartilhada com o Conselho Fiscal da Cooperativa, o que demonstra uma atuação transparente e responsável da instituição.

A estruturação do processo contemplou e avaliou, em relação aos candidatos, a adesão à função, as aspirações de longo prazo, o potencial e prontidão quanto à visão estratégica de crescimento e expansão, assim como o entendimento e compromisso com os programas sociais da instituição.

D - Por meio da transparência, da oportunidade para todos, da valorização das pessoas e da maneira verdadeira e responsável de quem conduz o processo.

Fonte: Elaborado pelos autores (2019).

No Quadro 4, a questão versa sobre a percepção e representação dos valores da cooperativa, como missão, visão e valores. O item mais citado foi transparência do processo, seguido de valorização, oportunidade de crescimento e participação. Esses valores estão incorporados à Sicredi: preservação irrestrita da natureza do negócio (cooperativa); respeito à individualidade do associado; valorização e desenvolvimento das pessoas; preservação da instituição como sistema; respeito às normas oficiais e internas; eficácia e transparência da gestão.

Quadro 5 - Como o atual processo de sucessão beneficia o crescimento da cooperativa

Na sua percepção, como o atual processo de sucessão beneficia o crescimento da cooperativa? Cite três aspectos. A:

Com certeza beneficia, pois:

- Permite a implantação de novas ideias;

- A imagem da empresa permite o crescimento dos profissionais;

- Tende a valorizar as pessoas.

B:

- Oportunidade interna;

- Processo de avaliação transparente;

- Oportunidade de novas Ideias.

$\mathrm{C}$ :

- O processo de sucessão, conduzido por uma consultoria externa, de forma estruturada, transparente e profissional gerou muita credibilidade no Quadro social;

- Em muitas cooperativas, sucessão é um tabu. Diante disso, estabelecer um processo aberto a todo o Quadro social, construído com os coordenadores de núcleo e com o conselho de administração, credencia a Sicredi Alto Uruguai ao posto de instituição inovadora em relação ao tema;

- O processo de sucessão, trabalhado em um momento de expansão e pleno crescimento, contribui para a evolução, porque a Cooperativa não "trava" seus projetos, mas os impulsiona cada vez mais. Ao mudar apenas o nome do Presidente, e não o planejamento estratégico de longo prazo, a Cooperativa comunica determinada segurança ao mercado, visto que se alicerça em uma estrutura segregada na gestão estratégica e executiva.

D:

- Incentiva as pessoas a se aperfeiçoar a cada dia.

- Escolha de pessoas com perfil, conhecimento, habilidades e atitudes em sinergia com o cargo.

- Transparência e clareza nos processos.

Fonte: Elaborado pelos autores (2019).

No Quadro 5, apresentam-se as respostas para o questionamento: de que maneira o atual processo de sucessão beneficia o crescimento da cooperativa? Os respondentes novamente citaram "transparência do processo", um item que se incorporou ao valor da empresa, está evidente na cultura organizacional, 
consequentemente, é importante para os colaboradores. Nesse sentido, pode-se observar quanto os colaboradores estão engajados nos valores institucionais, pois fazem deles também seus valores pessoais.

Quadro 6 - O processo de sucessão de cargos contempla o planejamento da cooperativa

Você acredita que o processo de sucessão de cargos contempla o planejamento da cooperativa, ou uma nova gestão deverá revisar o planejamento e conduzi-lo a rumos diferentes?

A - Entendo que não é pelo fato de outra pessoa estar assumindo que deverá revisar o planejamento de longo prazo. A hipótese de revisão pode surgir, desde que surja a necessidade de implementar outras estratégias que não estavam sendo visualizadas.

B - Acredito que mantermos as premissas da Evolução 20.30 .

C - Em nossa Cooperativa, estruturamos um planejamento de longo prazo que contempla estratégias para 15 anos, com ciclos quinquenais. Tais aspirações se alicerçam em quatro pilares: crescimento e sustentabilidade; relacionamento com o Quadro social; eficiência operacional; engajamento e performance do Quadro de colaboradores. Diante disso, o planejamento e os projetos de longo prazo não mudam com a sucessão, pois o nosso entendimento é de que o planejamento, os projetos e programas não pertencem a uma pessoa, independentemente de seu cargo, mas à instituição.

D - Acredito que, no momento, não, mas, em um mundo VICA, isso vai mudar e se aperfeiçoar, de acordo com a necessidade da cooperativa.

Fonte: Elaborado pelos autores (2019).

O Quadro 6 apresenta as respostas para a percepção do colaborador no que tange ao processo de sucessão de cargos. A questão examinada foi se contemplaria o planejamento da cooperativa ou se esse processo tomaria outros rumos. Os colaboradores acreditam que o processo de sucessão não vai alterar o planejamento de longo prazo da organização e que, em caso de eventuais ideias do novo gestor, as ações podem ser aperfeiçoadas.

Um planejamento estratégico, realizado em bases sólidas e pautado nas necessidades e aspirações da instituição, dificilmente sofrerá mudanças significativas, mesmo quando há troca de gestores na direção da empresa.

No Quadro 7, questionou-se aos colaboradores sobre hierarquia, processo de sucessão e perfil para o cargo. As respostas novamente contemplaram uma visão positiva. Os respondentes enxergam a hierarquia como uma estrutura sólida e eficiente e acreditam que o perfil se pauta basicamente nos valores difundidos pela instituição e citados em respostas anteriores. Para Scott, Jaffe e Tobe (1998, p. 23), os valores são como "a nossa energia, motivação e inspiração" e "estão na base de toda aprendizagem". Esse conceito se reafirma nas respostadas dos colaboradores que vivem os valores organizacionais de forma evidente. 


\section{Quadro 7 - Hierarquia na cooperativa}

Como você percebe o aspecto hierarquia na cooperativa? Na sua percepção, o atual processo de sucessão de cargos beneficiou a escolha de qual perfil de candidato? Aponte dois ou três dos principais pontos fortes e fracos do processo. Justifique.

A - Beneficia o candidato com melhor visão estratégica, pois essa é a grande missão de quem está em cargo de Diretoria.

Pontos fortes é a oportunidade de quem foi selecionado (e mesmo de quem não foi) criar um plano de desenvolvimento pessoal.

Ponto fraco não diz respeito ao processo em si, mas à necessidade de avançar na preparação dos profissionais que têm interesse em encarar novos desafios, pois o foco é, geralmente, preparar-se para a função atual e não para assumir novos desafios.

B - Acredito que o perfil condiz com o que o Conselho de Administração acredita ser o melhor para a Cooperativa. O que contribui para os cargos de sucessão são as experiências vividas dentro do sistema, a preparação para a formação profissional e a maturidade para o peso da cadeira.

$\mathrm{C}$ - A estrutura de governança em nossa Cooperativa é muito bem definida dentro da segregação da estratégia X execução, ou seja, a Direção Estratégica é composta por um Conselho de Administração gerida pelo Presidente e nove conselheiros, sendo que um deles acumula o cargo de Vice-Presidente. Esses conselheiros representam nove microrregiões e categorias profissionais que compõem o Quadro social da Cooperativa. Contamos também com coordenadores de núcleo que representam os "braços" do Conselho de Administração nos núcleos Cooperativos. No que diz respeito à Direção Executiva, a cooperativa atua com três Diretores: Executivo, Operações e Negócios. Diante do exposto, entendemos que a estrutura segregada e de governança "modela" a hierarquia, de forma que a Cooperativa possa crescer acima dos dois dígitos ao ano, sem se distanciar do associado.

- Acredito que o processo de sucessão desenvolvido na Cooperativa procurou identificar o candidato que mais se aproximava do perfil desejado, avaliando o potencial e prontidão em relação às necessidades da Cooperativa, considerando os desafios e projetos da instituição, porém sempre respeitando as competências e habilidades de cada um dos candidatos.

Pontos fortes:

-Transparência na construção do processo de sucessão;

-Contratação de uma consultoria externa para conduzir o processo de forma isenta e estruturada nos princípios, valores e aspirações estratégicas da Cooperativa.

Pontos fracos ou a melhorar:

-Apenas quatro candidatos se apresentaram para o processo, apesar da comunicação efetiva com o Quadro social; D - Perfil com forte relacionamento, propósito inspirador e alinhado com a cooperativa.

Fonte: Elaborado pelos autores (2019).

No Quadro 8, a questão versa sobre os estilos de liderança dos candidatos no processo sucessório e tem o objetivo de verificar se esse modelo de sucessão seria indicado a outras organizações. Todos os respondentes afirmam que o processo identifica os estilos de liderança e verifica as competências e habilidades de cada candidato. Por acreditarem tratar-se de um processo benéfico a qualquer tipo de organização, os colaboradores o indicariam a outras empresas.

Quadro 8 - Estilos de liderança.

O processo de seleção identifica os estilos de liderança dos candidatos? Você indicaria esse processo de sucessão a outras cooperativas ou empresas?

A - Com certeza indica, e, na metodologia que foi utilizada, eu indicaria.

B - Sem dúvidas, identifica. Esse processo cabe a qualquer organização.

C - Entendo que o processo estabelecido foi fundamental, visto que permitiu mapear as competências e habilidades de cada participante, identificar o perfil, conhecer as experiências vivenciadas e verificar o estado potencial e prontidão em relação ao momento da cooperativa.

Com certeza recomendaria esse processo para outras cooperativas, pois a consultoria contratada é especializada no tema, com ampla experiência no cooperativismo e no mercado que contempla instituições renomadas.

D - Sim, indicaria, para oportunizar a todos a possibilidade de demonstrar seu potencial e capacidade.

Fonte: Elaborado pelos autores (2019). 
O Quadro 9 apresenta as respostas quanto aos desafios percebidos pelos colaboradores na gestão da cooperativa de crédito. Os respondentes citaram: gestão de pessoas; alinhamento com a missão e valores institucionais; engajamento; crescimento sustentável. Nota-se a preocupação dos respondentes com uma estrutura administrativa que permita crescer e manter-se sustentável em longo prazo. As ações atuais são consideradas parte da construção da empresa e em constante evolução. Esse olhar se volta para os próprios princípios do cooperativismo com os quais os colaboradores se identificam.

Quadro 9 - Desafios na gestão da cooperativa de crédito.

No atual contexto, quais os principais desafios para a gestão da cooperativa de crédito?

A - Manter as equipes focadas em cumprir a nossa missão, sem ferir os valores diante da necessidade de atingir ou sustentar determinados resultados. Estes são a consequência do atendimento da nossa missão e das necessidades de nossos associados.

B - Gestão de pessoas; satisfação dos cooperados; indicadores de eficiência em face de um cenário econômico turbulento; concorrência. Também se observa um momento promissor do cooperativismo se ele for aplicado dentro da missão do ser Cooperativa.

$\mathrm{C}-$

- Percepção da entrega da missão da Cooperativa por parte do Quadro social e sociedade;

- Ser percebida pela sociedade como instrumento de desenvolvimento regional;

- Ser a guardiã dos princípios e valores do Cooperativismo e da Cooperativa, considerando o mercado competitivo e individualista que se apresenta;

- Participação efetiva do Quadro social nas decisões da cooperativa;

- Crescimento sustentável norteado pelo planejamento de longo prazo;

- Visão estratégica de longo prazo;

- Expansão vertical e horizontal.

D - Manter o engajamento dos colaboradores no propósito e inovação; manter um crescimento sustentável; inspirar e planejar a cooperativa e o cooperativismo para um futuro cada vez mais globalizado e tecnológico.

Fonte: Elaborado pelos autores (2019).

O engajamento dos colaboradores com a missão e a visão da instituição está presente em várias respostas deste estudo. Além do planejamento estratégico, às organizações é indispensável que o colaborador "vista a camisa" e paute-se nos princípios da instituição em que trabalha. Definir a missão é o primeiro passo da empresa no processo de planejamento e estabelecimento das metas e prioridades.

A missão conduz a empresa ao comprometimento, uma razão maior para o seu funcionamento. Desse modo, quando consegue difundir seus valores entre os respectivos colaboradores e fazer da sua a missão deles no desempenho das tarefas, a organização atinge um enriquecimento do capital humano incalculável.

\section{Conclusões}

O presente estudo apresentou uma análise do processo de sucessão na cooperativa de crédito Sicredi Alto Uruguai, RS, e a percepção dos gestores que participam desse processo inovador na organização. Um traço digno de consideração e observado a priori é o engajamento dos colaboradores entrevistados com a missão e os valores organizacionais.

Os colaboradores enxergam a sucessão como um processo transparente, que permite identificar a valorização profissional e a participação no crescimento sustentável da instituição. Desse modo, a 
satisfação, o comprometimento e o fato de sentir-se parte da empresa são fatores de uma dimensão incalculável. Por isso, é fundamental valorizar o potencial desses colaboradores, pois, sem pessoas para produzir, criar ideias e inovar, a organização não sobrevive.

Neste estudo, verificou-se que a valorização dos profissionais é uma das prioridades da instituição. A consequência disso é não só a melhoria dos resultados, mas também colaboradores que não se sentem mais uma peça da engrenagem, ao contrário, estão comprometidos, envolvidos e satisfeitos com o seu trabalho. Para manter o crescimento e a sustentabilidade a longo, a organização deve, portanto, fortalecerse e alicerçar-se nos devidos valores.

Verificou-se, ademais, que a instituição preza a transparência do processo sucessório, a valorização do conhecimento, a dedicação do colaborador e mantém a preocupação de atuar e estar em constante desenvolvimento na sociedade em que se insere. A qualificação dos candidatos demonstra uma atmosfera de incentivo contínuo de crescimento pessoal e profissional. O empenho para atingir um perfil capacitado para gerir a instituição possibilita, além da evolução organizacional, o crescimento pessoal e a motivação dos candidatos a gestores.

O clima organizacional da cooperativa de crédito Sicredi Alto Uruguai, RS, conforme os dados deste estudo, reflete o grau de satisfação dos membros no ambiente de trabalho. Existe, portanto, uma compatibilidade entre os valores e interesses individuais com as necessidades da organização. Diante disso, é possível afirmar, o processo sucessório nessa instituição revela que indivíduos e empresa compartilham os mesmos valores. Tal relação constitui o principal fator de excelência pessoal e organizacional.

\section{Referências}

ABRAPP. Guia de orientação de planejamento de sucessão: continuidade das atividades. 1 ed. São Paulo, 2017.

CHAVES, Sidney Soares. Cooperativismo de crédito e empresas de pequeno porte em arranjos produtivos locais. Tese (doutorado). Porto Alegre: UFRGS, 2009.

CRÚZIO, Helnon de Oliveira. Como organizar e administrar uma cooperativa. 4 ed. Rio de Janeiro: FGV, 2005.

GAWLAK, A.; RATZKE, F. A. Cooperativismo: primeiras lições. 4. ed. Brasília: SESCOOP, 2010.

GIL, A. C. Como elaborar projetos de pesquisa. 4. ed. São Paulo: Atlas, 2002.

SICREDI. Histórico do Sicredi. Disponível em: https://www.sicredi.com.br/html/conheca-osicredi/historico. Acesso em 27 out. de 2019.

HÜMMELGEN, Bruno. Cooperativismo: um agente de mudança. Revista Urutágua - Revista Acadêmica Multidisciplinar. Universidade Estadual de Maringá (UEM). n. 34, jun./ nov., 2016.

IBGC. Guia de orientação para planejamento de sucessão, avaliação e remuneração de conselho de administração e diretor-presidente. São Paulo: IBGC, 2011. 
IP, Barry. JACOBS, Gabriel. Planejamento de sucessão empresarial: uma revisão das evidências. Journal of Small Business and Enterprise Development, v. 13, n. 3, p. 326-350, 2006.

LAKATOS, E. M. Metodologia do trabalho científico. 8. ed. São Paulo: Atlas. 2017.

LIMA, Romeu Eugênio de. Desempenho das cooperativas de crédito que se transformaram para a modalidade de livre admissão. Dissertação (mestrado). Belo Horizonte: UFMG, 2008.

SANTOS, R. A. dos. Metodologia científica: a construção do conhecimento. 7. ed. Rio de Janeiro: DP\&A, 2007.

SCHNEIDER, José Odelso. Uma Relevante Herança Social do Padre Theodor Amstad. OCB, Fevereiro de 2014. Disponível em: http://cooperativismodecredito.coop.br/2014/02/uma-relevanteheranca-social-do-padre-theodor-amstad-por-jose-odelso-schneider/. Acesso em 19 de out. de 2019.

SOARES, M. M.; MELO SOBRINHO, A. D. Microfinanças: o papel do Banco Central do Brasil e a importância das cooperativas de crédito. Brasília: Banco Central do Brasil, 2008.

VIDIGAL, A.C. Viva a empresa familiar. Rio de Janeiro: Rocco, 1996.

YIN, R. Estudo de caso: planejamento e métodos. 4. ed. Porto Alegre: Bookman, 2010. 